\title{
The Surface of Mars
}

\author{
1. Cratered Terrains ${ }^{1}$
}

\author{
Bruce C. Murray, Laurence A. Soderblom, \\ Robert P. Sharp, and James A. Cutts \\ Division of Geological Sciences \\ California Institute of Technology, Pasadena 91109
}

\begin{abstract}
Mariner 6 and 7 pictures show that craters are the dominant landform on Mars and that their occurrence is not correlated uniquely with latitude, elevation, or albedo markings. Two distinct morphological classes are recognized: small bowl-shaped and large flat-bottomed. The former show little evidence of modifications, whereas the latter appear generally more modified than lunar upland craters of comparable size. A regional maria/uplands dichotomy like the moon has not yet been recognized on Mars. Crater modification on Mars has involved much greater horizontal redistribution of material than in the lunar uplands. It is possible that there are erosional processes only infrequently active. Analysis of the natures and fluxes of bodies that have probably impacted the moon and Mars leads to the likelihood that most of the large flat-bottomed craters on Mars have survived from the final phases of planetary accretion. Significant crater modification, however, has taken place more recently on Mars. Inasmuch as the present small bowl-shaped craters evidence little modification, the postaccretion crater-modification process on Mars may have been primarily episodic rather than continuous. The size-frequency distribution of impacting bodies that produced the present small Martian bowl-shaped craters differs from that responsible for post-mare primary impacts on the moon by a marked deficiency of large bodies. Survival of crater topography from the end of planetary accretion would make any hypothetical earthlike phase with primitive oceans there unlikely. The traditional view of Mars as an earthlike planetary neighbor in terms of its surface history is not supported by the picture data.
\end{abstract}

Perhaps the most exciting result of the Mariner 4 television experiment in 1965 was the discovery of cratered terrains on Mars, a generally unexpected addition to the annual development of the frost caps, seasonal darkenings, and other presumed earthlike phenomena. The television pictures returned by Mariners 6 and 7 in 1969 greatly extended knowledge of Martian cratered terrains and showed two new uncratered terrains as well. Close-up pictures were obtained of the south polar cap and also of certain prominent light-dark boundaries. These and other results of the television experiments were first discussed in three preliminary reports published shortly after receipt of the picture data [Leighton et al., $1969 a, b, c]$. The objective of this paper and of the three companion papers is to describe the results of subsequent analysis and interpretation of the

${ }^{1}$ Contribution 1891, Division of Geological Sciences, California Institute of Technology, Pasadena.

Copyright (C) 1971 by the American Geophysical Union.
Mariner 6 and 7 television pictures as they bear on the nature of the Martian surface. The present paper deals with the nature and significance of cratered terrains. The second is concerned with uncratered terrains [Sharp et al., 1971a]. The third paper discusses photographic observations relevant to the nature of light and dark markings [Cutts et al., 1971], and the fourth describes observations and implications of surface features of the south polar cap [Sharp et al., 1971b]. We shall refer to them as papers $1,2,3$, and 4 , respectively.

The picture data used are principally the 'maximum-discriminability' versions displayed in the accompanying papers by Dunne et al. [1971] in this issue, supplemented by other versions of the near- and far-encounter photography. Image-processing techniques are discussed in a separate paper in this issue [Rindfleisch et al., 1971]. Picture location and notation are summarized in the preceding article in this issue by Leighton and Murray.

Craters are visible in 52 of the 55 near-encounter frames (best resolution $0.3 \mathrm{~km}$ ) and 
constitute the principal landform observed. At this early stage of Martian exploration we define cratered terrains to be regions of the surface in which craters are the dominant, often the only, topographic forms recognizable at the resolution of the Mariner 6 and 7 pictures. Intercrater areas are included in this definition. As better pictures become available, more sophisticated criteria may have to be developed to categorize what may well be a variety of Martian terrains. We feel, nevertheless, that the surface processes and history of Mars inferred from the evidence of the terrains already recognized will provide a useful framework for more detailed information and knowledge to be acquired by future space missions.

In the following, the geographic distribution of cratered terrain is reviewed and possible correlations, with elevation, latitude, and albedo are considered. Morphology of local features and crater abundances is then treated. Martian observations are compared with those of the

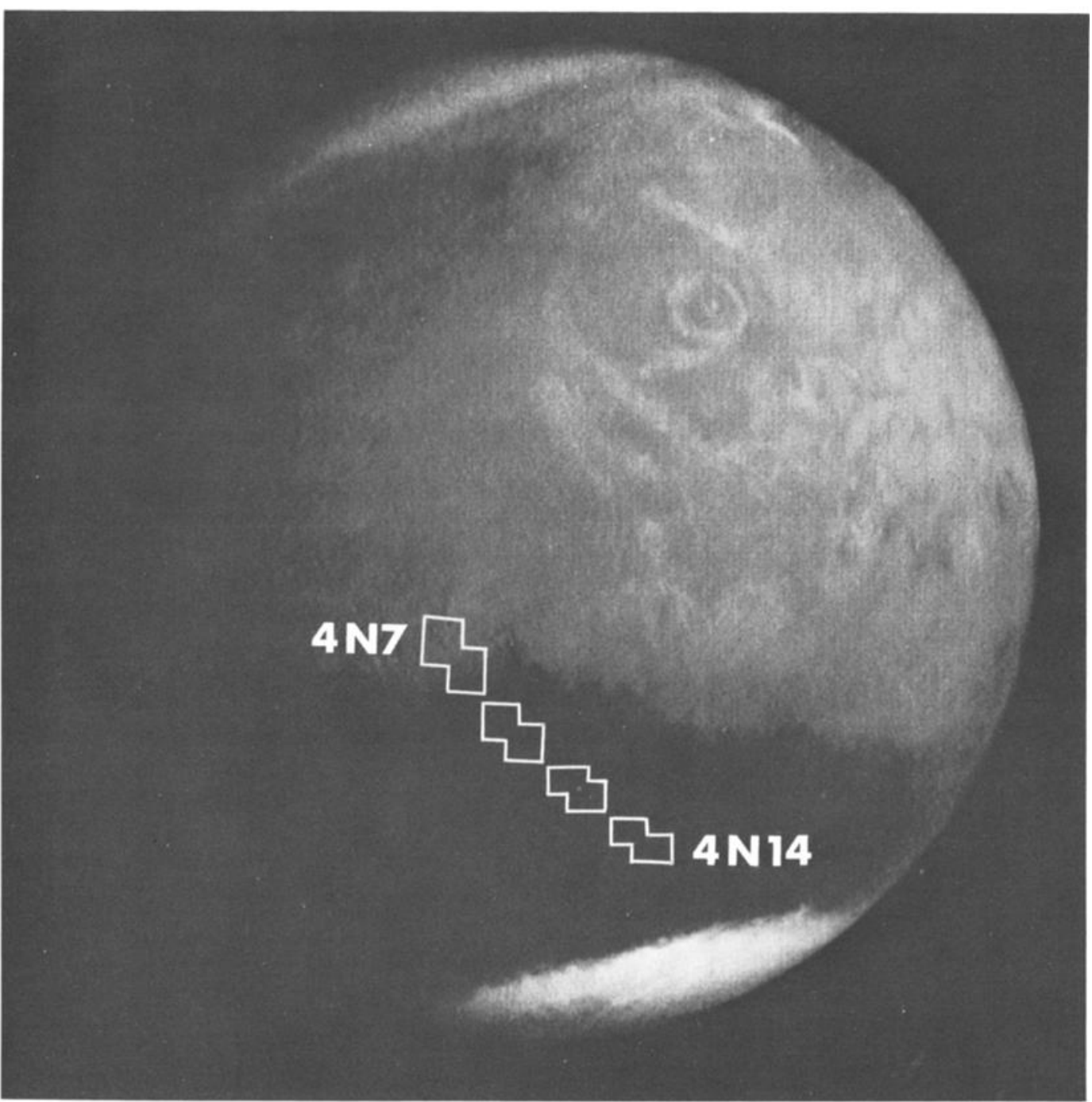

Fig. 1a. Positions of Mariner 4 photographs 4 N7 through $4 \mathrm{~N} 14$ plotted on Mariner 7 farencounter photograph $7 \mathrm{~F} 76$ with a sub-spacecraft longitude of $199^{\circ} \mathrm{E}$. The ringed structure, Nix Olympica, is visible in the northern hemisphere. 

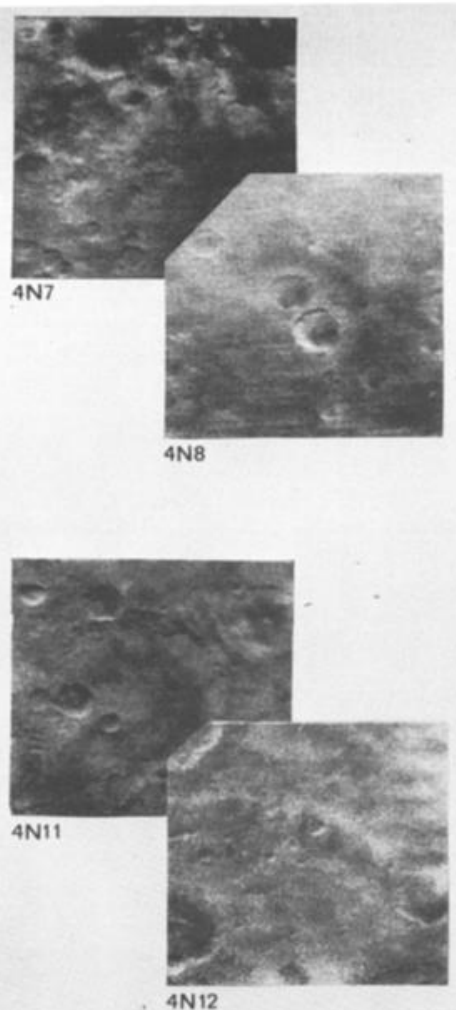

$4 \mathrm{~N} 12$
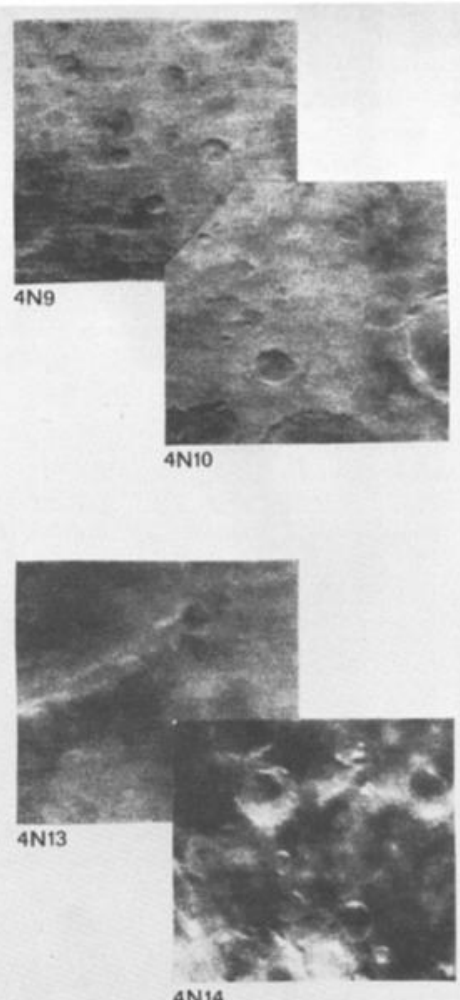

$4 \mathrm{~N} 14$

Fig. 1b. Cratered terrain displayed in Mariner 4 frames 4 N7 through 4 N14, taken across Zephyria, Mare Sirenum, Mare Cimmerium, and Phaethontis. (See paper 3 for identification of named features.) Frames $4 \mathrm{~N} 8$ and $4 \mathrm{~N} 13$ contain prominent light/dark boundaries. Individual frames are about $250 \mathrm{~km}$ on a side. Longitude, latitude, and solar elevation angle range from $186^{\circ} \mathrm{E}, 13^{\circ} \mathrm{S}, 61^{\circ}$ for $4 \mathrm{~N} 7$ through $209^{\circ} \mathrm{E}, 42^{\circ} \mathrm{S}, 29^{\circ}$ for $4 \mathrm{~N} 14$. Details are available in Leighton et al. [1967].

lunar-cratered terrains, leading to the conclusion that many large Martian craters, like those of the lunar uplands, have survived since the last phases of planetary accretion. The later history of Mars, however, appears to differ significantly from that of the moon. Finally, the traditional view of Mars as once having experienced earthlike conditions is reevaluated in light of the similarities of the Martian cratered terrain to the lunar uplands.

\section{Observations of Martian Cratered Terrains}

Cratered terrain on Mars was first revealed in television pictures returned by Mariner 4 in 1965. Mariners 6 and 7 extended the observations of cratered terrain sufficiently to demonstrate that it is the dominant Martian landscape; it is not uniquely correlated in occurrence with light or dark areas or with any particular elevation range, and it contains two distinct types of craters: large flat-bottomed and small bowlshaped. In this section we summarize the characteristics of Martian cratered terrain and compare it with the cratered terrain of the moon.

Geographic distribution. Craters ranging in diameter from a few hundred meters to a few hundred kilometers are visible in the Mariner 6 and 7 photographs. If this sample is representative, cratered terrain (including intercrater areas) constitutes at least $90 \%$ of the Martian surface.

Some very large craters are recognizable in the far-encounter frames of Mariner 6 and 7 , especially in the dark area Syrtis Major (frame 7 F87) and Mare Cimmerium (frame 7F82). The feature Nix Olympica, long recognized as a bright 
patch from earth-based observations, is seen at higher resolution (frame 7F77) to be a multiplering structure of maximum dimension exceeding $500 \mathrm{kms}$. Presumably this is at least the remnant of a very large crater. Circular features almost as large are faintly visible in bright areas within frames 7F83 and 7F84. The polar cap edge observed in the late far-encounter frames of both Mariner 6 and Mariner 7 is partly delineated by large craters up to $110 \mathrm{~km}$ in diameter (see
Figures 3 and 4 of paper 2 and Figures 1 and 2 of paper 4).

Figures 1b, 2, and 3 in this paper and Figure 3 in paper 4 are mosaics composed of the best nearencounter photography from Mariners 4, 6, and 7 . They all show predominately cratered terrain. Each of these mosaics is discussed briefly in the context of the regional associations of Martian cratered terrain.

Craters from 4 to $350 \mathrm{~km}$ in diameter are

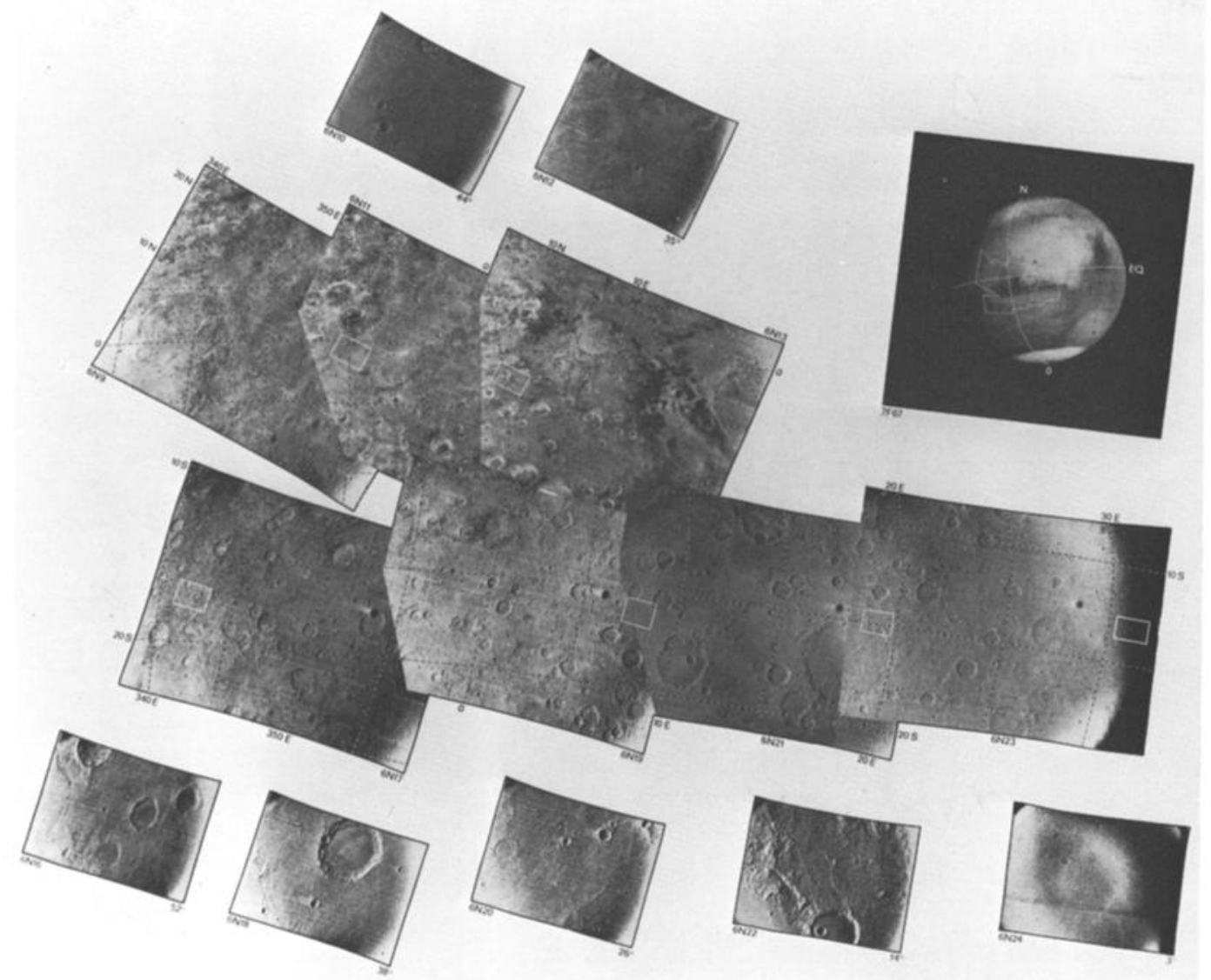

Fig. 2. Area of mosaic of frames $6 \mathrm{N9}$ through $6 \mathrm{~N} 23$, shown in outline on the far-encounter frame 7F67, including the dark areas Meridiani Sinus and Sabaeus Sinus and the light area Deucalionis Regio. (Geographic names are located in paper 3.) Solar elevation angles, which range from $52^{\circ}$ down to $3^{\circ}$ are shown at the lower right-hand corner of the $\mathbf{B}$ frames. The outline of these narrow-angle frames is shown in white on the mosaic of $A$ frames, along with latitude and longitude grid lines. Individual A frames are of the order of $1000 \mathrm{~km}$ in the long direction; B frames are $1 / 10$ scale of A frames. One degree of latitude on Mars is $59 \mathrm{~km}$. Maximum discriminability versions have been used that greatly accentuate topographic detail but distort and suppress some albedo marking, especially the outlines of Meridiani Sinus. The crater counts used in Figures 4, 5, and 6 are derived from frames $6 \mathrm{~N} 16$ to $6 \mathrm{~N} 23$ and refer principally to the Deucalionis Regio area. 


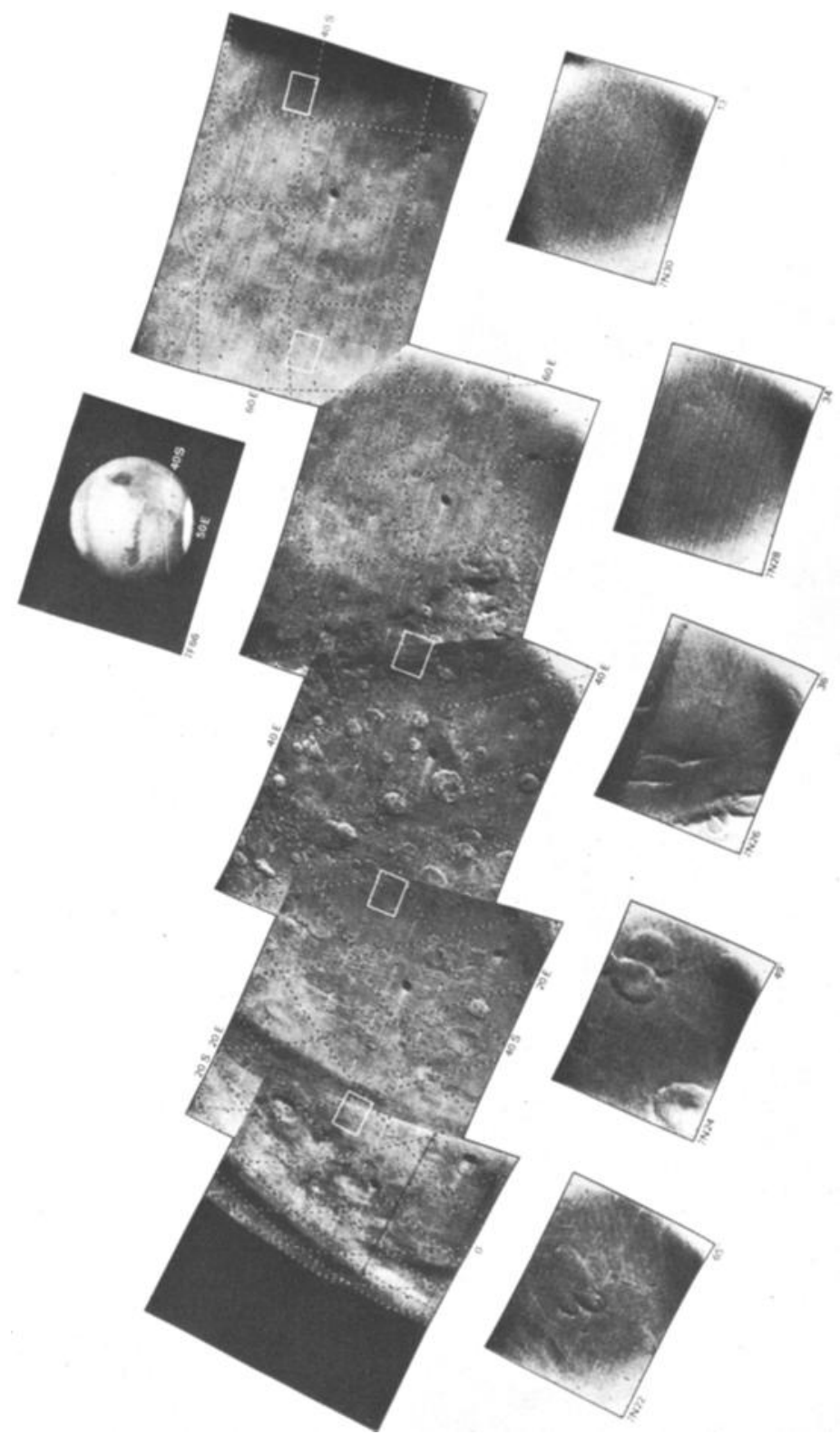

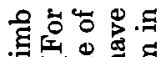

$\Phi$ is

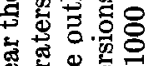

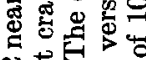

N

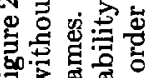

陆

岁造出

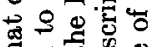

Tि

क.

늘 5.응 ०

का की

的

\&

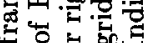

क 30

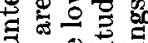

훙

甲

क्ष. 0 落

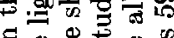

5。岂害



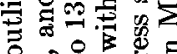

옹

$\cong$ 를

药

क

की

舟绕

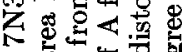

保出

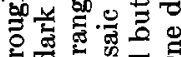



+ o응

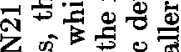

․

प3

8 .

承

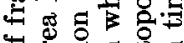

定.

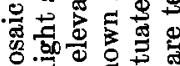

궁

政

证

o

边. 论

क

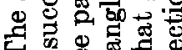

$\rightarrow$ क

ल के क्ष

.

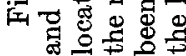


visible in Mariner 4 frames $4 \mathrm{~N} 5$ through $4 \mathrm{~N} 14$, as is shown in Figures $1 a$ and $1 b$. A prominent light/dark boundary, the northern boundary of Mare Sirenum, is included in the pair of frames $4 N 7 / 4 N 8$. Cratered topography does not appear to vary significantly across this boundary.

The near-encounter frames from Mariner 6 nearly all encompass cratered terrain except for small areas of chaotic terrain (see Figure 2 of paper 2). The mosaic of Figure 2 covering the equatorial areas Meridiani Sinus and Deucalionis Regio exhibits cratered terrain especially well and illustrates again that the general character of cratered terrain can remain unchanged across light/dark boundaries.

The near-encounter frames of Mariner 7, included in the mosaic of Figure 3, also display principally cratered terrains except for the featureless floor of Hellas. These frames show the presence of craters at southern midlatitudes $\left(20^{\circ}\right.$ to $\left.45^{\circ} \mathrm{S}\right)$.

The mosaic in paper 4 (Figure 3 ) demonstrates the occurrence of numerous craters under the south polar cap. Thus, craters are abundant in the equatorial, midlatitude, and south polar regions of Mars, evidencing no marked latitudinal dependence of cratered terrains. The continuation of craters across the Noachis/Hellespontus boundary (Figure 3) again demonstrates the absence of any unique correlation between light and dark areas and cratered terrain.

The distribution of cratered terrain has been examined for possible correlation with elevation. A limited quantity of reliable data on regional elevation has been obtained from ground-based radar observations [Goldstein et al., 1970; Lincoln Laboratory, 1970] and from equivalent width variations in $\mathrm{CO}_{2}$ absorption bands measured by the onboard infrared spectrometers of Mariners 6 and 7 [Herr et al., 1970]. Cratered terrain occurs over a wide range of elevations; no unique correlation with height is evident.

In summary, the cratered terrain of Mars is the most extensive terrain on the planet. It occurs over a wide range of latitudes and elevations and is not confined to either light or dark areas or to a particular elevation or latitude range.

Although variations in the character of the cratered terrain do occur [Cutts et al., 1971], they are not clearly defined, and the relationships with elevation, albedo, and latitude are complex.
By way of comparison, on the moon two distinct kinds of cratered terrain are evident that bear asimple relationship to height and light and dark markings. On the moon, large, highly-modified craters are restricted to the uplands. Mare formation presumably obscured most of the older preexisting craters in the maria basins. So, whereas the lunar uplands are rough, elevated, bright terrains containing numerous old flatfloored craters, the lunar maria are dark, low in elevation, smooth, and essentially devoid of old highly modified craters. Mariner 6 and 7 photographs do not reveal a similar regional association of Martian craters. First, both light and dark areas of Martian cratered terrain contain large flat-bottomed craters generally in comparable abundance. The lunar correlation of large degraded craters with high albedo and uplands is not evident on Mars. Hence, the characteristic association of crater form, elevation, and albedo denoted by the term 'mare' on the moon, is apparently absent on Mars, at least in those areas photographed in the nearencounters of Mariners 4, 6, and 7. Hellas, the large circular area of featureless terrain discussed in paper 2 of this series, might conceivably represent a mare-like surface even though it is of high albedo. However, the marked absence of any visible impact features would require it to be extremely young. A continuous process modifying the floor of Hellas seems more likely.

Topographic relief. A striking difference between the Martian and lunar surfaces is the lower relief of the walls of large craters (diameter $>15 \mathrm{~km}$ ) and of the intercrater areas on Mars. This was first recognized from the Mariner $4 \mathrm{TV}$ experiment [Leighton et al., 1965], although in that instance large spurious background light levels originating from some unknown optical degradation weakened the credibility of this conclusion [Young, 1969]. The Mariner 6 and 7 camera systems were free of such anomalous effects; the gentleness of Martian topography is again indicated.

Several specific lines of evidence are available. As is evident in Figure $7 a$, the horizontal width of walls of large flat-bottomed craters (diameter $>15 \mathrm{~km}$ ) on Mars is generally several times smaller than the width of walls of similar size craters on the moon. Thus the relief across such walls must be much less than on the moon, provided that the wall slopes on Mars are not 
correspondingly greater. It is clear that such is not the case because the conspicuous shadows that would be cast by such steep walls are not found. In addition, slopes of walls of large flatbottomed craters can be estimated from oblique views independently of the lighting conditions or photometric properties of the surface. This is done by assuming that these large craters are approximately radially symmetric and by comparing the projected widths of the near and far walls measured on a photograph. If the slopes are low, these apparent widths are nearly the same over a wide range of viewing angles. If the slopes are great (i.e., the order of the emission angle), then the relative apparent widths vary rapidly with emission angle. Such tests were made on two large flat-bottomed craters in the northeast corner of $6 \mathrm{~N} 16$ (emission angle $\sim 43^{\circ}$ ). Such estimates give slopes of the order of $10^{\circ}$; certainly they are not more than $20^{\circ}$. Finally, low average slopes on Mars are suggested by the rather narrow width of the marginal zone of the south polar cap. As is discussed more fully in paper 4 , the latitudinal width of that zone is probably controlled by the magnitude of crater slopes; average slopes of the order of $5^{\circ}$ or less on scale of several kilometers are indicated along the polar-cap edge. In summary, the relief of large flat-bottomed craters (diameter $>15 \mathrm{~km}$ ) on Mars is less, perhaps several times less, than that found on the moon, and the average slopes of large crater walls and of surrounding terrain also may be less than those found in the lunar uplands. Small bowl-shaped craters, however, may or may not differ significantly in form from fresh craters of the same diameter on the moon; that analysis is not yet complete.

Morphology of craters and associated features. Two distinct types of craters are distinguished in the areas viewed by Mariners 6 and 7 and are referred to here as small bowl-shaped and large flat-bottomed craters. No gradation between these two types has been observed so far; they are discussed separately here. A few ringed structures (6N20) and a considerable number of polygonal craters (6N13) have been recognized. This latter similarity to the moon may have structural implications.

Large flat-bottomed craters seen in Mariner 6 and 7 photographs range in diameter from about $15 \mathrm{~km}$ to several hundred $\mathrm{km}$. They are highly modified from their presumed initial appearance as impact craters. Rims are not detectable or greatly subdued, central peaks are rare, and other impact-associated features, such as secondary crater swarms and ejecta blankets, have been greatly modified, usually beyond recognition. Some of these craters, here termed vestigial or ghost, have been so greatly modified that the relief of their walls is only faintly visible. Other large flat-bottomed craters are much more easily recognized. These two states of preservation are well shown in frame 6 N16. We do not see a clear gradation between these two types of flat-bottomed crater; they may reflect a complex episodic phase of early Martian history.

Small bowl-shaped craters represent the majority of craters observed so far with diameters below 10 to $15 \mathrm{~km}$. These smaller craters exhibit almost all the associated impact phenomena found with lunar primary craters of similar size. The associated slump blocks and secondary crater swarms are not visible, as expected, as these would be below the limit of resolution. The small bowl-shaped craters appear to be of uniform morphology, indicative either of very little or very uniform modification.

A parallel is found in comparing the crater populations on Mars with those on the lunar uplands. Most of the large craters in the lunar uplands also have suffered significant modification (Figure $7 a$ ), as a result of which their ejecta blankets are no longer recognizable and secondary crater swarms have been obliterated. Many exhibit smooth, flat floors. Some have lost rims and central peaks as well. Also present in the lunar uplands are abundant fresh small craters (Figure $7 b$ ), which have suffered little, if any, modification. Thus, both the lunar upland and the Martian surfaces generally display two families of craters: abundant, flat-floored craters that have been significantly modified, and smaller craters that appear relatively unmodified. However, on Mars both classes show less variation in the degree of modification.

Important differences do exist between the lunar uplands and the Martian terrains. The Martian large flat-bottomed craters are less numerous and more highly modified than those observed on the moon. The intercrater areas on Mars are much smoother. Although the large flat-floored craters both on Mars and on the moon 
must have suffered periods of intense modification before the formation of the small fresh craters, the intensity or period, or both, of such modification on Mars, not only must have been greater, but also must have occurred principally after the formation of most of the large craters. Otherwise, some large fresh craters would be easily recognizable in the Mariner pictures, just as Copernicus, Tycho, and Kepler are conspicuous on the moon.

Martian cratered terrains also display a variety of positive and negative local features other than craters. Included are sinuous channels and ridges visible in many $B$-camera frames (see, for example, 6N16, 6N18, and 6N20). A series of subparallel short linear markings, in some instances composing polygonal patterns similar to those of the moon, is visible in the dark area, Sabaeus Sinus, in the northern parts of $6 \mathrm{~N} 19$ and $6 \mathrm{~N} 21$.

Certain diagnostic lunar and terrestrial surface features were looked for but not recognized in the Mariner pictures. Especially conspicuous is the absence of fresh large craters and their associated rays and secondary swarms. Such craters, like Tycho and Copernicus, are among the more striking features observed on the moon. Sinuous rilles, flow fronts, and partially flooded craters that characterize the lunar maria have not been observed. Finally, regional terrestrial features resembling folded mountains, island ares, continental/oceanic plates, and rift valleys are not recognized on Mars.

Size-frequency distribution of Martian craters. Cratered terrain on the moon traditionally has been described according to the number of craters per unit area as a function of diameter. In Figure 4 the cumulative number of craters per unit area larger than a given diameter is plotted against that diameter for the Martian area Deucalionis Regio. The relevant data are listed in Table 1.

Figure 5 shows the crater counts for the individual $\mathrm{A}$ and $\mathrm{B}$ frames that are averaged in Figure 4. Figure 5 demonstrates two aspects of the data: (1) major geographic variations in the density of large flat-bottomed craters are not present within Deucalionis Regio, nor are the apparent densities correlated with either solarelevation angle or A-camera filter, and (2) the statistical noise in the measurements of small bowl-shaped craters is large enough to mask

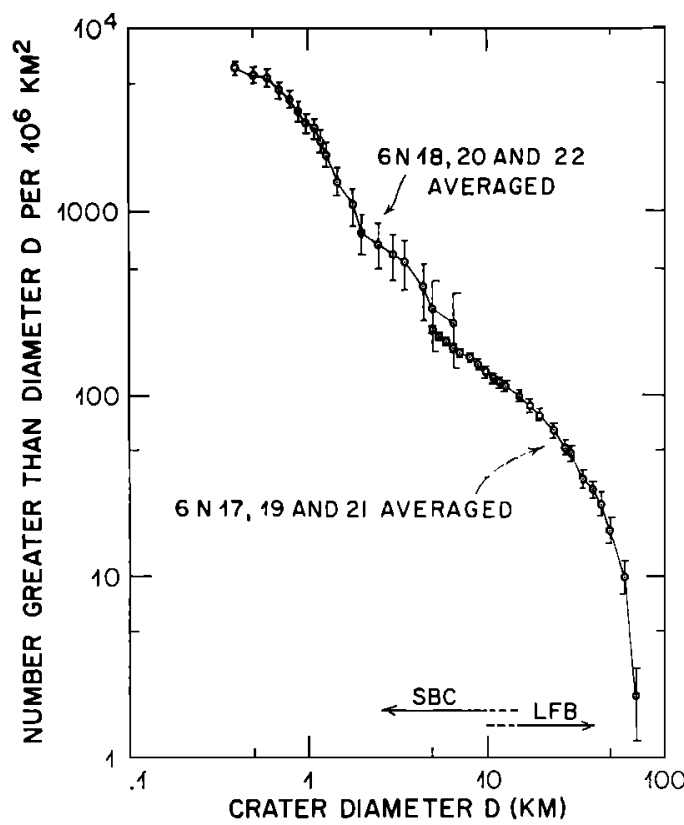

Fig. 4. Crater abundances of Deucalionis Regio. The cumulative crater-diameter relationship is plotted by using the numerical data of Table 1 . The vertical axis is a logarithmic scale of crater diameter. The range of crater diameters for small bowl-shaped and large flat-bottomed craters, respectively, is indicated approximately by arrows overlapping in the range of 10-15 km. Error bars have been derived on the basis of the expected statistical uncertainty in the actual number of craters counted. Thus, the errors are largest for the largest (and therefore fewest) craters counted in either A or B frames.

any genuine geographic variation or small solar-elevation angle effect.

It would be desirable to have size-frequency data separately for the large flat-bottomed and small bowl-shaped populations. Unfortunately, the resolution of the $\mathrm{A}$ frames is inadequate to confidently separate the two classes in the important 5-15 kilometer range, and the areal coverage of the $B$ frames, which do possess adequate resolution, is insufficient to provide adequate crater counts in the same interval, as shown by the error bars in Figure 4. Thus we have included both populations in Figure 4 and merely note on it the approximate size ranges of the two classes.

\section{Martian Surface Processes and History}

The observed characteristics of the Martian 
TABLE 1. Martian Crater Abundances (Deucalionis Regio Area)

\begin{tabular}{|c|c|c|c|}
\hline $\begin{array}{l}\text { Diameter } \\
\text { Interval, } \\
\mathrm{km}\end{array}$ & $\begin{array}{l}\text { Number } \\
\text { Counted }\end{array}$ & $\begin{array}{l}\text { Cumulative } \\
\text { Number }\end{array}$ & $\begin{array}{c}\text { Cumulative } \\
\text { Number } / 10^{6} \\
\mathrm{~km}^{2}\end{array}$ \\
\hline \multicolumn{4}{|c|}{$\begin{array}{l}\text { Average of Wide-Angle Frames } 6 N 17,6 N 19, \\
\text { and } 6 N 21\end{array}$} \\
\hline$\leq 41$ & 3 & $579 \pm 241$ & $250 \pm 10.3$ \\
\hline $4.2=4.5$ & 7 & $572 \pm 23.9$ & $247 \pm 102$ \\
\hline $46-50$ & 34 & $538 \pm 23.2$ & $233 \pm 100$ \\
\hline $5.1-5.5$ & 46 & $492 \pm 22.2$ & $213 \pm 9.6$ \\
\hline $56-60$ & 35 & $457 \pm 21.4$ & $198 \pm 9.3$ \\
\hline $6.1-7.0$ & 58 & $399 \pm 20.0$ & $172 \pm 8.6$ \\
\hline $71-8.0$ & 25 & $374 \pm 19.3$ & $162 \pm 8.4$ \\
\hline $8.1-9.0$ & 28 & $346 \pm 186$ & $150 \pm 8.1$ \\
\hline $9.1-100$ & 34 & $312 \pm 17.6$ & $136 \pm 77$ \\
\hline $10.1-11.0$ & 20 & $292 \pm 17.1$ & $126 \pm 7.4$ \\
\hline $11.1-12.0$ & 16 & $276 \pm 16.6$ & $119 \pm 7.2$ \\
\hline $121-13.0$ & 13 & $263 \pm 162$ & $114 \pm 7.0$ \\
\hline $13.1-15.0$ & 31 & $232 \pm 15.2$ & $100 \pm 6.6$ \\
\hline $151-18.0$ & 29 & $203 \pm 14.2$ & $88 \pm 6.2$ \\
\hline $181-20$ & 22 & $181 \pm 135$ & $78 \pm 5.8$ \\
\hline $21-24$ & 33 & $148 \pm 122$ & $64 \pm 5.2$ \\
\hline $25-30$ & 37 & $111 \pm 10.6$ & $48 \pm 4.5$ \\
\hline $31-35$ & 29 & $82 \pm 9.1$ & $35 \pm 38$ \\
\hline $36-40$ & 12 & $70 \pm 8.4$ & $30 \pm 3.6$ \\
\hline $41-45$ & 13 & $57 \pm 75$ & $25 \pm 33$ \\
\hline $46-50$ & 16 & $41 \pm 64$ & $18 \pm 2.8$ \\
\hline $51-60$ & 17 & $24 \pm 4.9$ & $10 \pm 21$ \\
\hline $\begin{array}{r}61-70 \\
>70\end{array}$ & $\begin{array}{r}19 \\
5\end{array}$ & $\begin{array}{l}5 \pm 2.2 \\
0\end{array}$ & $2.2 \pm 1$ \\
\hline \multicolumn{4}{|c|}{$\begin{array}{c}\text { Average of Narrow-Angle Frames } 6 \text { N18, } 6 \text { N20, } \\
\text { and } 6 \text { N22 }\end{array}$} \\
\hline$\leq 055$ & 11 & $113 \pm 106$ & $5600 \pm 530$ \\
\hline $0.56=0.65$ & 3 & $110 \pm 10.5$ & $5500 \pm 520$ \\
\hline $066-0.75$ & 16 & $94 \pm 9.7$ & $4700 \pm 480$ \\
\hline $0.76-0.85$ & 10 & $84 \pm 9.2$ & $4200 \pm 450$ \\
\hline $086-0.95$ & 12 & $72 \pm 85$ & $3600 \pm 420$ \\
\hline $0.96-1.05$ & 10 & $62 \pm 79$ & $3100 \pm 390$ \\
\hline $1.06-1.15$ & 4 & $58 \pm 76$ & $2900 \pm 380$ \\
\hline $116-1.25$ & 8 & $50 \pm 7.1$ & $2500 \pm 356$ \\
\hline $1.26-1.40$ & 8 & $42 \pm 65$ & $2100 \pm 320$ \\
\hline $1.41-170$ & 12 & $30 \pm 5.5$ & $1500 \pm 270$ \\
\hline $1.71-2.15$ & 8 & $22 \pm 4.7$ & $1100 \pm 230$ \\
\hline $216-2.30$ & 6 & $16 \pm 4.0$ & $800 \pm 200$ \\
\hline $2.31 \pm 270$ & 2 & $14 \pm 3.7$ & $700 \pm 190$ \\
\hline $2.71-3.5$ & 2 & $12 \pm 35$ & $600 \pm 170$ \\
\hline $36-4.5$ & 3 & $9 \pm 3.0$ & $450 \pm 150$ \\
\hline $4.6-5.7$ & 3 & $6 \pm 25$ & $300 \pm 120$ \\
\hline $58-78$ & 1 & $5 \pm 2.2$ & $250 \pm 110$ \\
\hline $7.9-9.9$ & 1 & $4 \pm 20$ & $200 \pm 100$ \\
\hline $10-20$ & 2 & $2 \pm 14$ & $100 \pm 70$ \\
\hline $21-27$ & 1 & $1 \pm 1$ & $50 \pm 50$ \\
\hline & 1 & 0 & \\
\hline
\end{tabular}

crater terrains have been compared with those of the uplands and maria of the moon. This section examines the implications of this comparison for Martian history and surface processes.

Review of lunar impact history. A valuable approach to understanding the evolution of the lunar surface has been the analysis of crater sizefrequency distributions. These crater populations record the energy-frequency distributions of impacting bodies (i.e., the mass-frequency distribution for given impact velocities) as well as the net effectiveness of crater-removal processes. Analysis of surfaces of differing age can elucidate

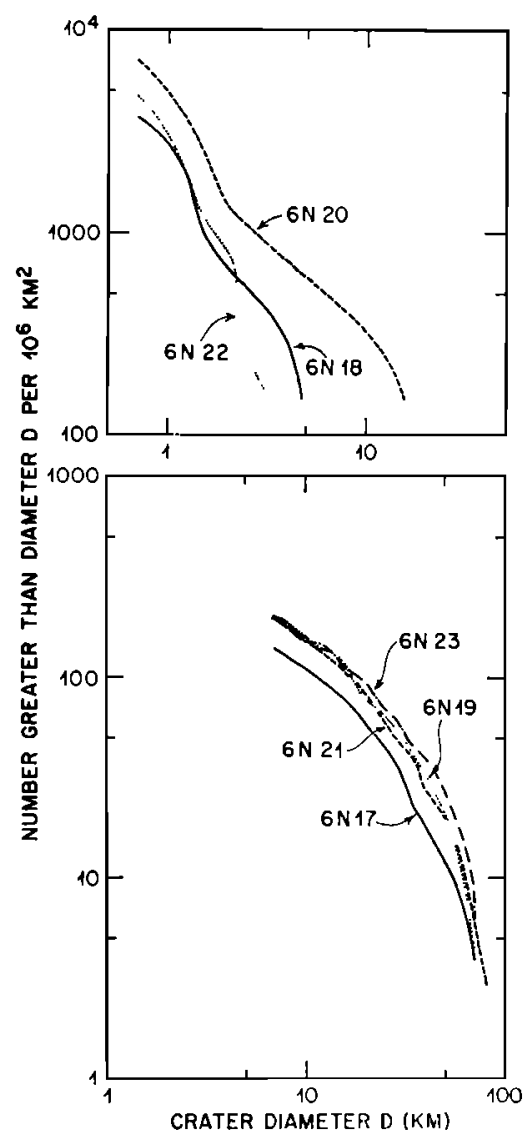

Fig. 5. Plots of crater abundances similar to those in Figure 4 are presented for individual Mariner frames. The narrow-angle B frames (top) show considerable variation in the large craters, mainly because of the limited number of craters; it is also possible that some minor geographic variations in crater abundances are included. Neither A nor B frames show any correlation with solar elevation angle, thus ruling out a potential source of systematic error. 
temporal variations in impact fluxes and in surface processes. The size-frequency distributions of lunar craters and the impact-flux histories implied for the earth-moon environment are reviewed here as background for the discussion of Mars.

Figure 6 shows typical crater size-frequency distributions for lunar surfaces of differing age: two maria and two upland regions. The crater populations on the younger surfaces, the maria, are less complicated by historical variation in impact flux, and it is appropriate to begin the discussion there. Craters of diameter larger than about $3 \mathrm{~km}$ are generally attributed to primary impacts [Shoemaker, 1965]. Such craters appear sharp and fresh, with raised rims, rays, ejecta blankets, and surrounding secondaries; in the larger size range, they exhibit central peaks. Although the magnitude of this primary crater distribution may vary significantly between maria of different age, the form of the distribution remains nearly unchanged [Kuiper et al., 1966; Trask, 1966]. For example, Trask found that the exponents of the power functions representing the size-frequency distributions of craters at the Ranger 7 and 8 sites are very nearly the same, whereas the total number of craters in this size range (diameter $>3 \mathrm{~km}$ ) differ by about a factor of 3 . Thus through the period of the evolution of the lunar maria the form of the mass-frequency distribution of impacting bodies has been constant.

It is possible to predict the population of secondary impact craters to be expected with this primary distribution. By studying the secondary populations of nuclear craters and large lunar primaries, Shoemaker [1965] and Brinkmann [1966] predicted that the secondary distribution will have a greater ratio of small to large craters and should exceed the primary popu-

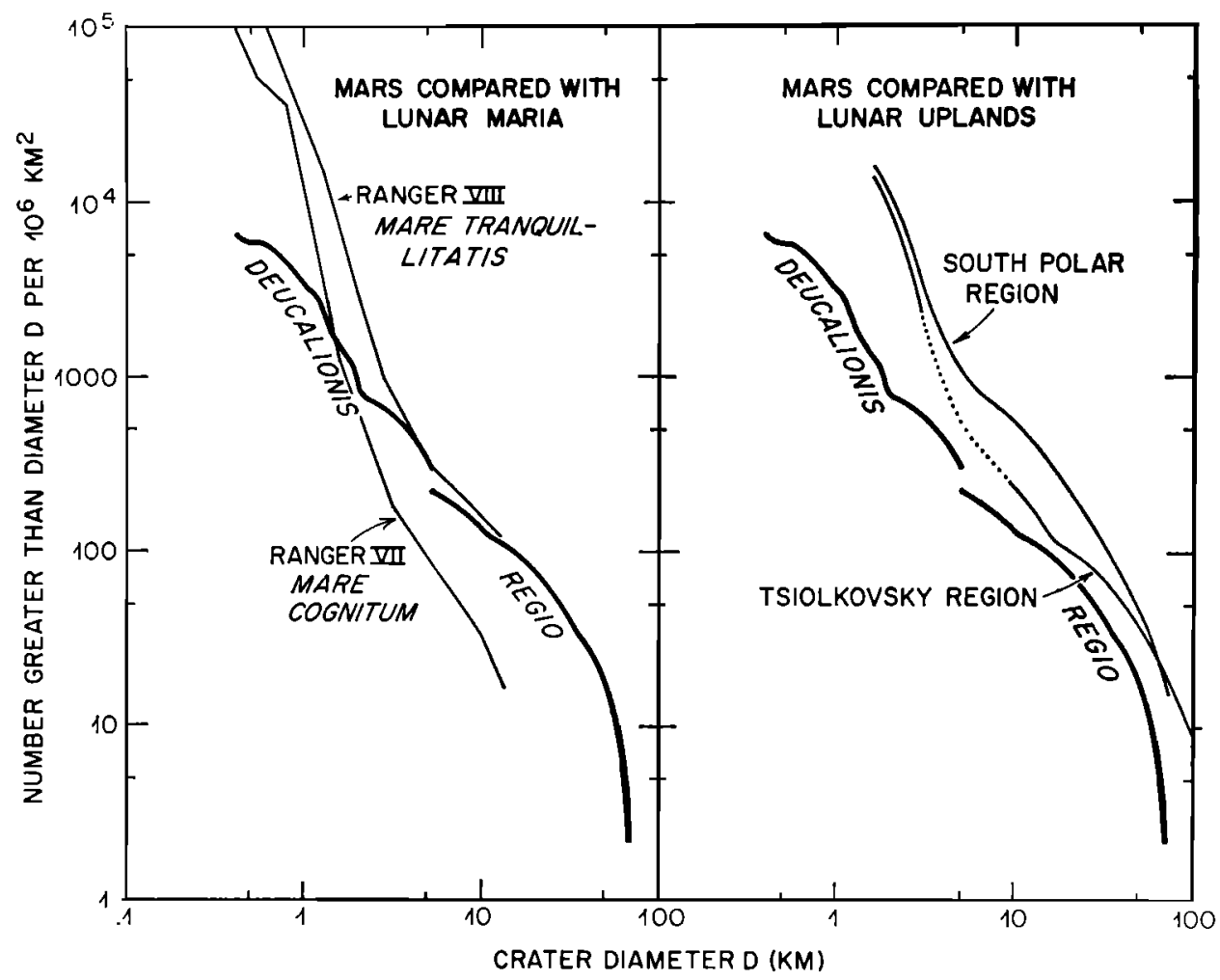

Fig. 6. The Deucalionis Regio data of Figure 4 are compared with crater abundances of the lunar maria (left) and the uplands (right). The Ranger 7 and 8 data are from Trask [1966]. The uplands data were compiled for this paper from Orbiter 4 frame 88, taken in the vicinity of the south pole, and Orbiter 3 frame 121 from the lunar backside near Tsiolkovsky, chosen because they appear to be free of effects of Mare formation. 
lation for craters of diameter smaller than about $1 \mathrm{~km}$. The steep part of the maria curves, for craters smaller than $3 \mathrm{~km}$, is compatible with these predictions (Figure 6). The distribution of large telescopically observable secondaries supports this hypothesis [Shoemaker, 1965].

Below diameters of about 100 meters the rate of increase of lunar crater density with decreasing diameter falls to a lower value than expected for a secondary population. Craters in this size class range from fresh and pristine to nearly obliterated shallow irregular depressions. This distribution of morphologies has led observers to conclude that these smaller craters form a steady-state population in which craters are formed and destroyed at the same rate [Moore, 1964; Shoemaker, 1965]. Soderblom [1970] has shown that the relationship between the steady-state population and the secondary production curve can be derived analytically from a model of downslope transport of material by impacts that produce negligible individual topographic changes.

In summary, the various segments of the crater frequency curves for craters in the lunar maria are related in recognizable ways. Primaries larger than a few kilometers produce abundant secondaries smaller than $1 \mathrm{~km}$. The erosive action of small secondaries (diameter $<10$ meters) on other large secondaries produces a steady population in which craters are generated and obliterated at the same rate.

Interpretation of the size-frequency relationship of craters in the lunar uplands is complicated by superposition of the later impact history recorded in the lunar maria on earlier cratering, which produced the very numerous large highlymodified craters. Under the assumption of constant flux rates throughout the history of the moon, the relative densities of large craters ( $>20 \mathrm{~km}$ in diameter) on the $\sim 4$-b.y.-old mare surface in Mare Tranquilitatis [Albee et al., 1970; Silver, 1970] and in the lunar uplands would imply an age for the uplands greater than 50 b.y. This unrealistic age estimate, coupled with the observed severe modification of the large upland craters leads to two conclusions: (1) the dense population of large craters in the lunar uplands records a period during which the cratering rate was orders of magnitude greater than has occurred since the formation of the maria, and (2) the uplands represent the accretional surface of the moon. (We shall ignore the possible complexities in the actual events that may have constituted the terminal phases of accretion and the immediate period thereafter. We presume a smooth and rapid decline of cratering rates at the end of accretion of both the moon and Mars.)

To return to the significance of the Martian crater abundances, a comparison of size-frequency distributions of craters in Deucalionis Regio and in the lunar maria and uplands is also presented in Figure 6. Martian cratered terrain and the lunar uplands both display large subdued craters and small bowl-shaped craters. The overall forms of the distributions are similar. However, the size-frequency distribution of the Martian small bowl-shaped craters is significantly different from that of comparably sized craters on the moon. The implications of these similarities and differences are considered in the next two sections.

Age of large flat-bottomed Martian craters. The age of large flat-bottomed Martian craters can be estimated by extrapolation of lunar cratering history. Lunar inpact fluxes can be extrapolated to Mars on some basis, and the Martian surface ages obtained by scaling with known surface ages on the moon. This was first attempted by Anders and Arnold [1965]. A more complete analysis was performed by Hartmann [1966] using Mariner 4 crater counts. Hartmann's analysis indicated that these Martian craters are at least $4 \pm 2$ b.y. in age. We argue here that Hartmann's result is a significant underestimate of the age of these craters when reviewed in light of current information.

Hartmann assumed that both the lunar and the Martian impact fluxes were entirely asteroidal and used a previous estimate by Anders [1964] of asteroidal fluxes at Mars higher by a factor of 25 . This factor of 25 is probably grossly overestimated, as indicated by a variety of reasons. First, Wetherill [1968] has shown by dynamical arguments that the probability of Mars being impacted by an asteroidal object whose orbit was perturbed by Mars is very low. This consideration significantly reduces the figure of a factor of 25. Second, the assumption that the impacting debris would preferentially impact Mars rather than the moon by a factor of 25 is not consistent with meteorite observations. Studies of meteorite orbits from observations of meteor trails have shown that most of the debris 
impacting the earth at present is in highly eccentric orbits with aphelion distances of 4 to $5 \mathrm{AU}$ [Wetherill, 1969]. Objects in such eccentric orbits would have almost equal likelihood of striking Mars and the moon. Furthermore, recent evidence of decreasing impact fluxes during the period of lunar formation (L. A. Soderblom and L. A. Lebofsky, unpublished data, 1970) suggests that a significant fraction of the lunar crater population was produced by cometary impact, or at least by a source other than asteroidal. An asteroidal impact flux would tend to increase with time [Kuiper, 1950; Öpik, 1951]. Further, as will be shown in the next section, the distributions of objects forming the present small craters (diameter $<10 \mathrm{~km}$ ) on Mars and on the moon have been different. Hence this factor of 25 must be a significant over-estimate, since impact fluxes on Mars and on the moon cannot both have been entirely asteroidal. The true ratio may be closer to unity, since objects in cometary orbits have almost equal probability of striking the earth and Mars. Finally, the large flat-bottomed Martian craters have been severely modified, and it is likely that many are no longer recognizable in the Mariner pictures. Hence, crater counts are on the low side compared to counts on the moon. All these arguments tend to increase the Hartmann-model age estimate to something far exceeding the age of the solar system. This, of course, is under an assumption of constant flux. The implication is, then, that these large flat-bottomed craters on Mars were formed, as were those in the lunar uplands, during the early history of the planet under very great fluxes. As in the case of the moon, we associate such conditions with the final phases of planetary accretion.

A second set of arguments also suggests that the large flat-bottomed craters on the moon and Mars record analogous stages of planetary evolution. The sequence of early events on Mars and on the moon were evidently similar. Both surfaces show an old, now-subdued population of numerous large craters that are ancient by any scaling, although the Martian population has been more severely modified and no longer displays the saturation that is seen in the lunar uplands. The size-frequency distributions of the lunar and Martian large craters are similar in botl amplitude and form. Both show evidence of major epochs of surface modification concurrent with or postdating the formation of these large craters. Both show a collection of younger, fresher craters that have accumulated since the end of major surface modification. Thus, not only are the Martian cratered terrains unquestionably ancient, but they mimic to some extent the sequence of events recorded on the lunar uplands. We feel it is probable, therefore, that both the Martian cratered terrain and the lunar uplands record the final stages of planetary accretion.

Differences in post-accretional histories. Major modification of large flat-bottomed craters on both the moon and Mars must have occurred before formation of the present relatively unmodified small crater populations on those surfaces. Small bowl-shaped craters on Mars appear comparable in degree of modification to craters of the same size (diameters 1-10 km) on the lunar maria. A comparison of these two distributions should expose differences and similarities in the size spectra of impacting objects that have created them.

The size-frequency distribution of primaries in the lunar maria can be written

$$
N=A D^{-1.7}
$$

where $N$ is the number of craters per unit area with diameters larger than $D$ and $A$ is a constant. Thus, for example, the ratio of the numbers of craters larger than $3 \mathrm{~km}$ to the number larger than $30 \mathrm{~km}$ for the lunar maria is about 50 . From Figure 4, the number of small bowl-shaped craters larger than $3 \mathrm{~km}$ in each A frame (area $\sim 0.6 \times 10^{6} \mathrm{~km}^{2}$ ) is about 400 . Hence, if the proportion of 3- to $30-\mathrm{km}$ Martian bowl-shaped craters were the same as the proportion on the moon, one would expect to see about 8 fresh bowl-shaped craters larger than $30 \mathrm{~km}$ in each A frame. Or, stated differently, 1 in 5 of the large flat-bottomed craters in Deucalionis Regio that are larger than $30 \mathrm{~km}$ in diameter should be as fresh and sharp as the small bowl-shaped craters and should appear similar to Kepler and Copernicus on the moon. Of the approximately 100 large flat-floored craters in Deucalionis Regio with diameter greater than $30 \mathrm{~km}$, none resembles the large youthful lunar craters.

In order to explain this evident deficiency, one might presume that large Copernicus-like craters on Mars rapidly assume the morphology of large flat-floored craters. It is indeed conceivable that the floors could quickly become flat. It is 
difficult, however, to imagine how rims, ejecta blankets, and secondaries could be obliterated without destroying the presently observed small bowl-shaped craters. It does not seem likely that the large craters of a contemporaneous population could be severly altered without even more severly modifying the smaller ones. Thus, the distribution of impacting bodies that formed the presently observed small bowl-shaped craters on Mars is deficient, by comparison to the lunar distribution, in objects that would produce craters like Copernicus and Kepler. That is to say, the postulated Copernicus-type craters and the present small bowl-shaped craters are not part of the same population (not that there never were any Copernicus-type events).

Another observation supporting the conclusion that recent Martian fluxes recorded by the small bowl-shaped craters were deficient in objects capable of forming a Copernicus-type crater is the lack of associated secondary craters. If the Martian primary distribution were similar to the lunar one, there would be a secondary population much like that represented by the steep sections of the crater-frequency relations for Mare Tranquilitatis and Oceanus Procellarum (Figure 6). The secondary distribution produced by the observed small bowl-shaped craters, however, should exceed the density of primary craters only for crater diameters less than 100 meters which is below the limit of resolution in Mariner 1969 pictures. The absence of not only Copernicus-sized fresh Martian craters, but of their associated secondaries as well, reinforces the important conclusion that the distributions of impacting objects that produced the present Martian small bowl-shaped craters and the postmaria lunar craters have been distinctly different.

Two possible explanations of these differences in accumulated impacts can be suggested. First, the populations of impacting bodies might be composed of several families of objects (e.g., asteroids and comets) present in different relative abundances at Mars and at the moon. A second, alternative possibility is that the ratio of cometary to asteroidal impacts has not been significantly different in the vicinities of Mars and the moon at any particular time but that this ratio has been changing over time. Thus the two surfaces now record accumulations over different time scales (this could result, e.g., in moon averages over abundant comets and later asteroids and Mars averages only over the later asteroids). Both kinds of effects may be responsible for the differences in the observed distributions.

The absence of Copernicus-like craters in Deucalionis Regio indicates still another important difference between lunar and Martian history. Copernicus, and Kepler, for example, presumably were formed on the moon by either cometary or asteroidal impact. If cometary, approximately the same number of such craters should have been formed on Mars as on the moon, since comets are typically in highly eccentric orbits. If Copernicus and Kepler are of asteroidal origin, there may have been a greater number of such impacts on Mars than on the moon [Anders and Arnold, 1965; Witting et al., 1965; Baldwin, 1965]. Either way, such craters must have formed on Mars in at least as great a number as are now evident in the lunar maria and at about the same time. Thus, $10-20$ of the approximately 250 large flat-bottomed craters in frames $6 \mathrm{~N} 17$, $6 \mathrm{~N} 19$, and $6 \mathrm{~N} 21$ must be no older than Mare Tranquilitatis $\left(\sim 4 \times 10^{9} \mathrm{yrs}\right)$. Yet all appear to have suffered about the same degree of modification, or we should recognize the younger fraction easily. Hence major modification of the large Martian craters must have occurred after the period of mare formation on the moon, i.e., within the last 3 to 4 b.y.

Martian crater-modification processes. Martian crater morphologies reflect crater-modification processes; therefore, they can supply insight into the nature of those processes. Small bowl-shaped craters on Mars all display about the same degree of preservation. Those observed appear fresh, having suffered only minor modification, if any. However, any earlier generations of Martian bowl-shaped craters have all been modified beyond recognition. Two possible explanations for these relationships merit examination: (1) episodic surges of crater formation coupled with continuous modification, and (2) episodes of catastrophic crater removal superimposed on an approximately continuous rate of crater formation. It is difficult from present information to evaluate confidently the relative importance of these two possibilities. However, the first appears to us less likely for two reasons. Studies of the chemical nature and cosmic-ray exposure ages of terrestrial meteorite falls [Anders, 1964] suggest that as many as 5 to 20 
families of meteoritic fragments have been produced by collisions in the asteroid belt in the last few hundred million years. Theoretical analyses of the lifetime of these fragments [Wetherill, 1967s Hartmann, 1968] indicate that the half-life for such families is of the order of $10^{8}$ to $10^{\circ}$ years. Thus the lifetimes are much longer than the intervals between the production events. Hence it seems unlikely that such surges of impacts of asteroidal objects have occurred on Mars (although this restriction may not apply to cometary objects). Overlap of differing families would lead to a distribution in the state of preservation of small bowl-shaped craters. Secondly, a continuous erosion process capable of rapidly removing traces of all preexisting small bowl-shaped craters
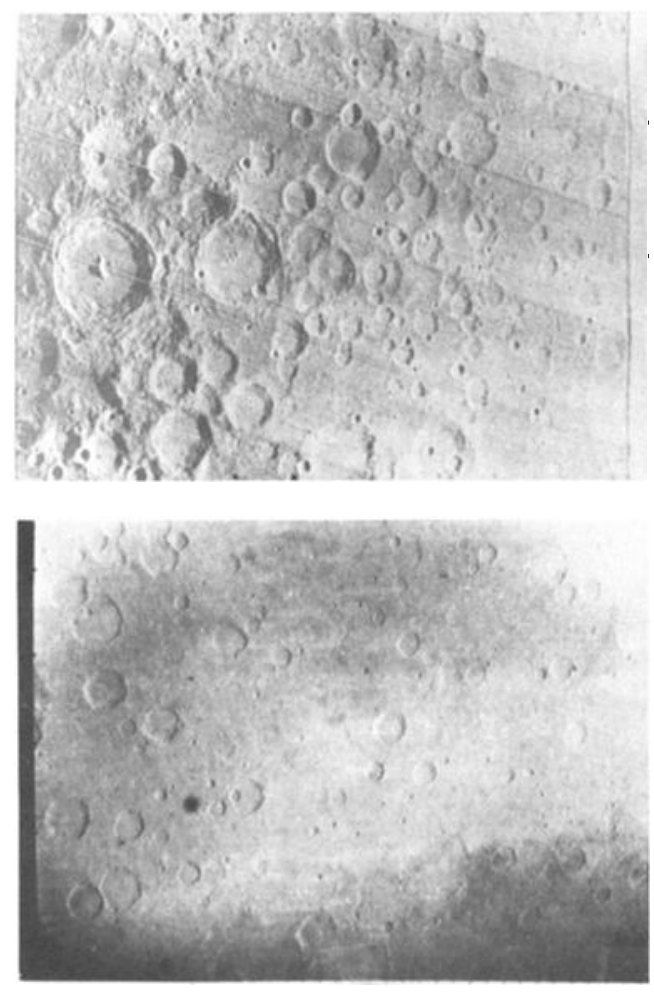

would probably eventually obliterate the large craters as well. Infrequent episodes of crater removal, however, might serve to remove large numbers of small craters without wearing down the large flat-bottomed craters significantly. Finally, in view of the unusual and recent surface modification processes implied by featureless and chaotic terrains (see paper 2), we prefer to place the emphasis of explanation on hypothetical episodes of crater removal rather than on hypothetical episodes of formation.

The nature of Martian surface processes can be further evaluated in the light of another significant observation. As illustrated in Figure $7 a$, intercrater areas in Martian cratered terrains are much smoother than in the lunar uplands
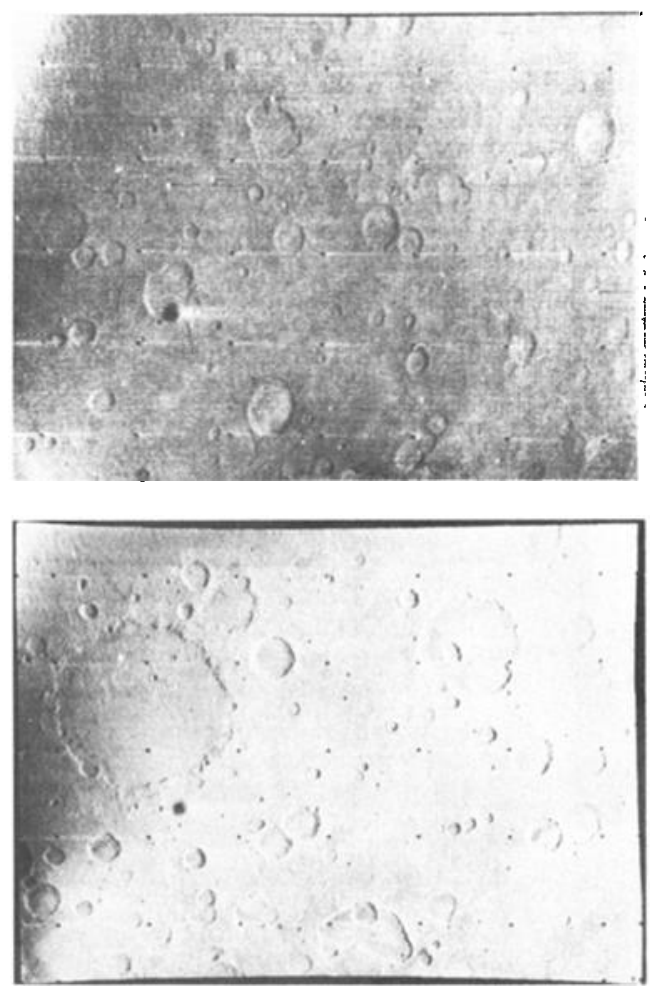

Fig. 7a. Lunar simulation of Mariner A frame. To illustrate the morphology of the lunar uplands at the same surface scale of the Mariner 6 and 7 wide-angle frames, a portion of medium-resolution frame 130 of the Lunar Orbiter Mission 4 has been enlarged so that the scale of the lefthand side of the frame approximates that of the accompanying Mariner frames $6 \mathrm{~N} 17,6 \mathrm{~N} 19$, and 6N21 (upper right, lower left, and lower right, respectively). Because of the smaller radius and therefore greater curvature, of the moon, complete simulation of wide-angle frames is not possible. The solar elevation angle in the lunar frame ranges from $50^{\circ}$ to $14^{\circ}$, thereby covering most of the range of the three Mariner frames. The contrast of the lunar frame has been artificially modified to resemble that of the Mariner frames. The lunar area is in the vicinity of the south pole, an upland region of the moon that has not been severely affected by adjacent mare formation and filling. 

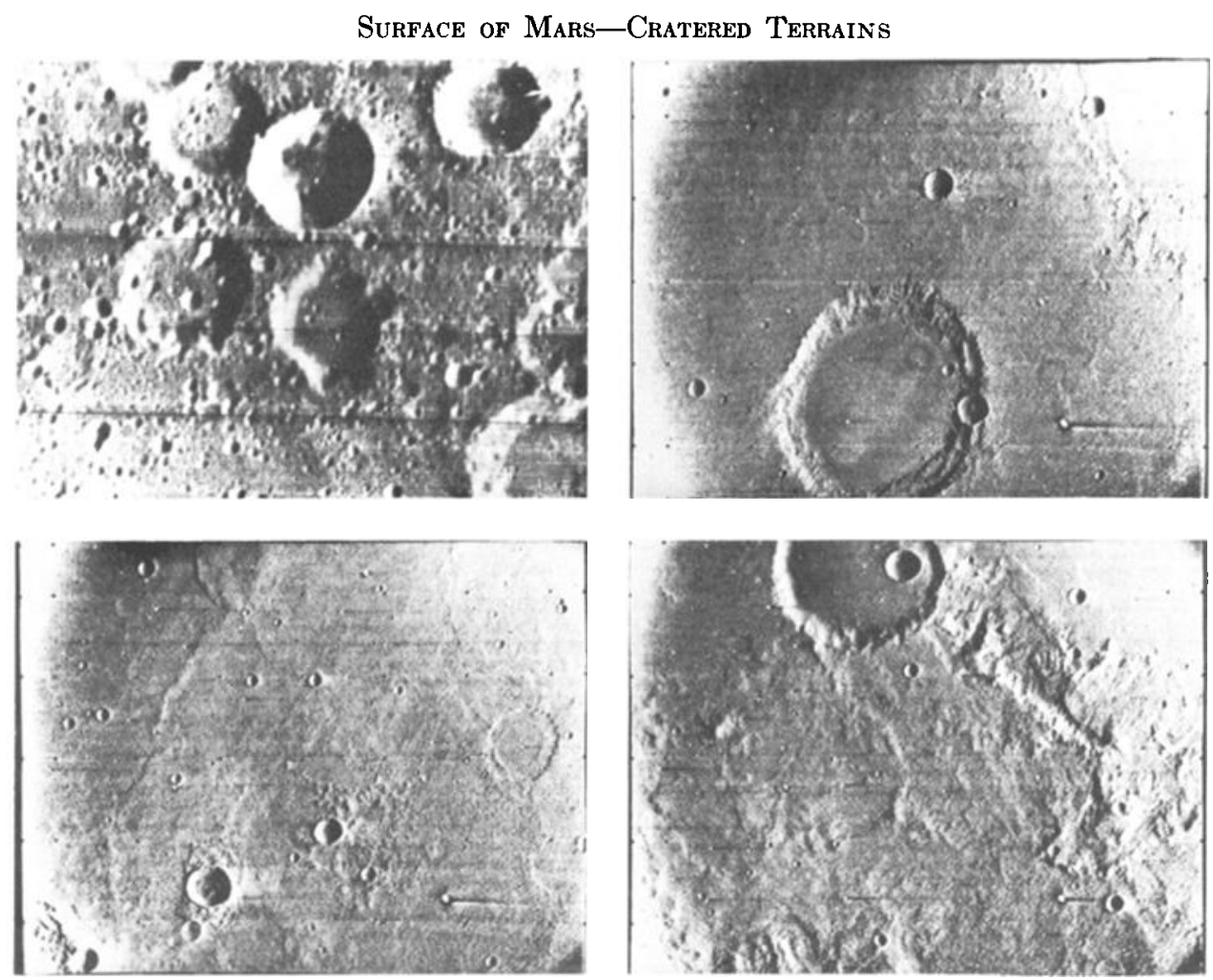

Fig. 7b. Lunar simulation of Mariner B frame. A similar procedure to that of Figure $7 a$ has been carried out to match the surface scale of Mariner narrow-angle frames $6 \mathrm{~N} 18,6 \mathrm{~N} 20$, and $6 \mathrm{~N} 22$. The solar elevation angle of the lunar area is $22^{\circ}$ and those of the Mariner frames are $38^{\circ}, 26^{\circ}$, and $14^{\circ}$, respectively. The lunar simulation is taken from Orbiter 4 high-resolution frame 107 (longitude $6^{\circ}$, latitude $-42^{\circ}$ ).

Both are thought by us to represent original accretionary surfaces, but the Martian surface has undergone a much greater degree of leveling and horizontal redistribution of material. This process has caused the disappearance of elevated crater rims and ejecta sheets, yet has permitted the survival of what is apparently primary relief along crater walls (see 6N18, Figure $7 b$ ). Local processes modifying lunar terrains are impact fragmentation and downslope transport by sliding, rolling, and impact ejecta, These proccesses tend to smooth out local topographic irregularities. If the Martian modification process of redistributing material depended principally on local impact events, as on the moon, it would seem that local relief along crater walls should have been smoothed out before the intercrater areas were leveled. Hence, the processes which have modified the surface of Mars may have been fundamentally different from those operative on the moon.

A natural inclination to call on solely aeolian processes to effect a regional redistribution of materials on Mars is complicated by the following considerations. Very effective physical or chemical weathering of consolidated rock is required to reduce original relief of hundreds of meters or kilometers completely into dust and sand-sized particles that could then be effectively transported by the Martian winds. By comparison, the dominant fragmenting process on the moon results from impact of high-velocity particles. As pointed out previously [Leighton et al., 1967], the effectiveness of this process on Mars would be greatly reduced by the thin atmosphere. Inasmuch as liquid water cannot exist in a free state on Mars owing to the low surface pressures [Ingersoll, 1970], and that thermal shattering is 
most likely ineffective [Ryan, 1962], the mechanism of effective weathering on Mars remains unknown.

Episodic crater obliteration might be related to occasional but extreme changes in the nature of the Martian atmosphere. Thus the Martian terrain, like that of much of the western United States where the odd thunderstorm is the major eroding event, may display the effects of erosional processes that are inactive during average conditions.

Summary. Comparison of regional associations, morphologies, and size-frequency distributions of craters on Mars and on the moon suggests the following conclusions concerning Martian surface history and processes:

1. The process of mare formation that has generated unsaturated and relatively unmodified cratered terrain on the moon subsequent to accretion is not evident on Mars.

2. Many of the large flat-bottomed craters on Mars probably have survived since the final stages of accretion of that planet.

3. The large craters on both Mars and the moon record intense modification. However, the lack of large fresh Martian craters, comparable to Kepler and Copernicus on the moon, implies that the substantial large-crater modification on Mars took place during the last 3-4 b.y. after major modification had ended on the moon. However, no significant modification process appears to have been operative during the interval of the accumulation of the present small bowl-shaped craters.

4. The average distributions of impacting bodies that formed the currently visible small craters on Mars and of the lunar maria have been different.

5. Modification of the surface on Mars has been accompanied by much greater horizontal redistribution of material than has occurred on the moon.

\section{Comparison with the Surface Evolution of Earth and Moon}

There has been a traditional interest in Mars as a possible abode of simple life forms. For many decades preceding spacecraft investigation, Mars was viewed as possibly having experienced an earthlike phase with aqueous atmosphere and possibly primitive oceans in which simple life forms might have evolved [de Vaucouleurs, 1950;
Kuiper, 1952, pp. 3, 343-444; Shirk et al., 1965; National Academy of Sciences, 1966a, 1966b; Shklovskii and Sagan, 1966]. The pictures from Mariners 4, 6, and 7 now provide a concrete framework for Martian surface history. The survival of large Martian craters for, at the very least, several billion years, and indeed most probably from the end of planetary accretion, places strong constraints on the surface history of Mars relevant to the possibility of any earthlike period. Unlike earth, neither crustal deformation nor atmospheric erosion has been sufficient to destroy these ancient Martian topographic features. Thus there is, for Mars as well as for the lunar uplands, the implication of a stable crust and the absence of an earthlike aqueous atmosphere with great erosional capabilities.

It is difficult to be precise as to exactly how 'lunarlike' or 'non-earthlike' Mars must be in order to satisfy present observations. At the very least, it can be argued that the most probable early history of the surface of Mars is much like that of the moon. Two kinds of evidence from Mariner 6 and 7 picture analysis support this conclusion. The first pertains to the magnitude of and response to crustal deformation. Like the lunar uplands, the Martian cratered terrain has been exceedingly stable for eons, undisturbed by earthlike tectonic activity. Further, the structural properties of the lunar and Martian crusts must be similar to account for the corresponding development of polygonalization of large craters on both surfaces. The second kind of evidence supporting a 'lunarlike' Mars is the strikingly similar sequence of early events recorded on both bodies. The Martian cratered terrain and the lunar uplands preserve remnants of old crater populations that are similar in morphology, areal density, and size-frequency distribution, and that are highly modified. Both surfaces record a stage of initial high-impact flux followed by intense surface modification that grossly degraded craters and ceased before the accumulation of most of the presently visible small bowl-shaped craters. These similarities strongly suggest that the near-surface crustal environment of Mars has been lunarlike since its earliest history. There is no present evidence of any terrestrial phase or processes. Thus, there is little more basis for postulation of ancient oceans on Mars than on the moon. Brief earthlike pe- 
riods cannot be rigorously ruled out for either body, but such events are less likely for moon and Mars than for Venus, or perhaps even Mercury whose surface history is not so constrained by observations as that of Mars.

The importance of this kind of comparative planetology argument lies in its implication for planetary exploration generally. The reduced probability of Martian oceans, implied by the presence of primordial cratered terrains there, surely means a significant reduction in the probability that life could have originated on Mars in an earthlike manner. The basis for emphasis on Mars as the prime target in the search for extraterrestrial life seems to be weakened by the strong resemblance of its surface to the uplands of the moon. Rather, Mars should be accorded priority geologically as exhibiting important aspects of planetary evolution unknown elsewhere in this solar system, such as the replacement of cratered terrains by younger uncratered terrains, as will be discussed in paper 2. Only on Mars can there be found a carbon dioxide frost cap with all its associated phenomena. There are erosional processes and modification episodes recorded on the Martian surface unlike those yet known on any other body. The unraveling of these characteristically Martian processes and the associated surface history provides a compelling and rewarding intellectual focus for exploration of that planet.

Acknowledgments. We are deeply indebted to all persons whose combined efforts made the Mariner 1969 flights to Mars a success. With respect to the series of four articles on Martian surface features published herein, we specifically acknowledge the valuable aid of the following: G. E. Danielson, S. A. Collins, J. J. van der Woude, T. C. Rindfleisch, J. A. Dunne, R. C. Dewar, and Patricia Conklin, all of the California Institute of Technology and JPL. Our colleagues of the Mariner TV team, M. E. Davies, A. H. Herriman, N. H. Horowitz, C. B. Leovy, B. A. Smith, and A. T. Young have provided counsel and information. Without the leadership and unending efforts of Principal Investigator R. B. Leighton, the TV project would never have succeeded. Robert $\mathrm{A}$. West of the California Institute of Technology assisted in preparation of crater counts. The present paper has been substantially revised from its original form to take into account the careful and constructive criticism received from a number of reviewers, and we wish to acknowledge their contribution.

The participation of Murray, Leighton, and Sharp has been underwritten by the California
Institute of Technology. Cutts has been partly supported by NASA-105-69836 and Soderblom by NGL-0.5-002-003.

\section{RefFrFnces}

Albee, A. L., I). S. Burnett, A. A. Chodos, O. J. Eugster, J. C. Huneke, D. A. Papanastassiou, F. A. Podosek, G. Price Russ II, H. C. Sanz, F. Tera, and G. J. Wasserburg, Ages, irradiation history, and chemical composition of lunar rocks from the Sea of Tranquillity, Science, 167, 463$466,1970$.

Anders, E., Origin, age, and composition of meteorites, Space Sci. Rev., 3, 583-714, 1964.

Anders, E., and J. Arnold, Age of craters on Mars, Science, 149, 1494-1496, 1965.

Baldwin, R. B., Mars: An estimate of the age of its surface, Science, 149, 1498-1499, 1965.

Brinkmann, R. T., Lunar crater distributions from Ranger VI photographs, J. Geophys. Res., 71, 340-342, 1966.

Cutts, J. A., R. P. Sharp, B. A. Smith, B. C. Murray, and L. A. Soderblom, The surface of Mars, 3, Light and dark markings, J. Geophys. Res., 76, this issue, 1971.

de Vaucouleurs, G., The Planet Mars, pp. 7172, Faber and Faber, London, 1950.

Dunne, J. A., W. D. Stromberg, R. Ruiz, A. Collins, and T. E. Thorpe, Maximum discriminability versions of the near-encounter frames, $J$. Geophys. Res., 76 , this issue, 1971.

Goldstein, R. M., W. G. Melbourne, G. A. Morris, G. S. Downs, and D. A. O'Handley, Preliminary radar results of Mars, Radio Sci., 5, 475-478, 1970.

Hartmann, W. K., Martian cratering, Icarus, 5, $565-576,1966$.

Hartmann, W. K., and A. C. Hartmann, Asteroid collisions, Icarus, 8, 361-381, 1968.

Herr, K. C., D. Horn, J. M. McAfee, and G. C. Pimentel, Martian topography from Mariner 6 and 7 infrared spectra, Astrophys. J., $75(8)$, 883-894, 1970.

Ingersoll, A. P., Mars: Occurrence of liquid water, Science, 168, 972-973, 1970.

Kuiper, G. P., On the origin of asteroids, Astronom. $J ., 55,164,1950$.

Kuiper, G. P., The Atmospheres of the Earth and Planets, pp. 343-344 and 404, University of Chicago Press, 1952.

Kuiper, G. P., R. G. Strom, and R. S. LePoole, Interpretation of the Ranger records, in Ranger 8 and 9, 2, Experimenters' Analyses and Interprelations, Jet Propul. Lab. Tech. Rep. 32-800, 35Q48, 1966.

Leighton, R. B., B. C. Murray, R. P. Sharp, J. D. Allen, and R. K. Sloan, Mariner 4 photography of Mars: Initial results, Science, 149, 627-630, 1965.

Leighton, R. B., B. C. Murray, R. P. Sharp, J. D. Allen, and R. K. Sloan, Mariner 4 pictures of Mars, Jel Propul. Lab. Tech. Rep. 32-884, 1967.

Leighton, R. B., N. H. Horowitz, B. C. Murray, 
R. P. Sharp, A. H. Herriman, A. T. Young, B. A. Smith, M. E. Davies, and C. B. Leovy, Mariner 6 television pictures: First report, Science, 165, 684-690, 1969a.

Leighton, R. B., N. H. Horowitz, B. C. Murray, R. P. Sharp, A. H. Herriman, A. T. Young, B. A. Smith, M. E. Davies, and C. B. Leovy, Mariner 7 television pictures: First report, Scrence, 165, 787-795, $1969 b$.

Leighton, R. B., N. H. Horowitz, B. C. Murray, R. P. Sharp, A. H. Herriman, A. T. Young, B. A. Smith, M. E. Davies, and C. B. Leovy, Mariner 6 and 7 television pictures: Preliminary analysis, Science, 166, 49-67, 1969c.

Leighton, R. B., and B. C. Murray, One year's processing and interpretation-An overview, $J$. Geophys. Res., 76, this issue, 1971.

Lincoln Laboratory, Radar Studies of Mars, Final Rep., Contract NAS 9-7830, 15 January 1970.

Moore, H. J., Density of small craters on the lunar surface, in Astrogeologic Studies Annual Progress Report, August 1962-July 1969, part D, pp. 34-51, U. S. Geological Survey, Washington, D. C., 1964.

National Academy of Sciences, Biology and the Exploration of Mars, pp. 8 and 21, Nat. Acad. Sci., Nat. Res. Council Publ. 1296, $1966 a$.

National Academy of Sciences, Space Research: Directions for the Future, pp. 18 and 96, Nat. Acad. Sci. Nat. Res. Council Publ. 1403, $1966 b$.

Öpik, E. J., Collision probabilities with the planets and the distribution of interplanetary matter, Proc. Irish Acad., 54, Sec. A, 1951.

Rindfleisch, T. C., J. A. Dunne, H. J. Frieden, W. D. Stromberg, and R. Ruiz, Digital processing of the Mariner 6 and 7 pictures, J. Geophys. Res., 76 , this issue, 1971.

Ryan, J. A., The case against thermal fracturing at the lunar surface, $J$. Geophys. Res., 67, 2549$2558,1962$.

Sharp, R. P., L. A. Soderblom, B. C. Murray, and J. A. Cutts, The surface of Mars, 2, Uncratered terrains, J. Geophys. Res., 76, this issue, 1971a.

Sharp, R. P., B. C. Murray, R. B. Leighton, L. A. Soderblom, and J. A. Cutts, The surface of Mars,
4, The south polar cap, J. Geophys. Res., 76, this issue, $1971 b$.

Shirk, J. S., W. A. Hazeltine, and G. C. Pimentel, Sinton bands: Evidence of deuterated water on Mars, Science, 147, 48-49, 1965.

Shklovskii, I. S., and C. Sagan, Intelligent Life in the Universe, p. 270, Holden-Day, San Francisco, Calif., 1966.

Shoemaker, E. M., Preliminary analysis of the fine structure of the lunar surface in Mare Cognitum, in The Nature of the Lunar Surface, pp. 23-78. Johns Hopkins Press, Baltimore, Md., 1965.

Silver, L. T., Uranium-thorium-lead isotopes in some Tranquility Base samples and their implications for lunar history, in Proceedings of the Apollo 11 Lunar Science Conference, 2, Chemical and Isotope Analysis, Geochim. Cosmochim. Acta, Suppl. 1, 1533, 1970.

Soderblom, L. A., A model for small-impact erosion applied to the lunar surface, J. Geophys. Res., 75, 2655-2661, 1970.

Trask, N. J., Size and spatial distributions of craters estimated from Ranger photographs, in Ranger 8 and 9, 2, Experimenters' Analyses and Interpretations, Jet Propul. Lab. Tech. Rep. 32-800, 249-338, 1966.

Wetherill, G. W., Collisions in the asteroid belt, J. Geophys. Res., 72, 2429-2444, 1967.

Wetherill, G. W., Dynamical studies of asteroidal and cometary orbits and their relation to the origin of meteorites, in Origin and Distribution of the Elements, edited by L. H. Ahrens, pp. 423-443, Pergamon, New York, 1968.

Wetherill, G. W., Origin of prairie network fireballs and meteorites (abstract), Trans. $A G U, 50$, 224, 1969.

Witting, J. F., F. Narin, and C. A. Stone, Mars: Age of its craters, Science, 149, 1496-1498, 1965.

Young, A. T., High-resolution photometry of a thin planetary atmosphere, Icarus, 11, 1-23, 1969.

(Received July 31, 1970; revised September 17, 1970.) 